\title{
Perancangan Sistem Pengontrolan Water Treatment Menggunakan Kontrol PID Septian Syahputra ${ }^{1}$, Hendy Santosa ${ }^{1}$, Faisal Hadi ${ }^{1}$. Program Studi Teknik Elektro, Fakultas Teknik, Universitas Bengkulu E-mail:, blastd14@gmail.com
}

\begin{abstract}
ABSTRAK
Air minum adalah air yang melalui proses pengolahan atau tanpa proses pengolahan yang memenuhi syarat kesehatan dan dapat langsung diminum. Perusahaan daerah air minum (PDAM) sebagai perusahaan air minum belum dapat sepenuhnya menyediakan air bersih bagi masyarakat karena masih banyak mengalami kendala-kendala. Penelitian ini bertujuan untuk merancang dan membuat alat water treatment menggunakan sistem kendali PID dengan metode trial \& error. dengan melihat parameter kekeruhan dan $\mathrm{pH}$ pada air yang menjadi syarat air layak minum. Alat ini terdiri atas perangkat keras dan perangkat lunak, perangkat keras terdiri atas sensor $\mathrm{pH}$, sensor kekeruhan, dan motor servo. Sedangkan perangkat lunak terdiri atas aplikasi arduino IDE(Integrated Development Environtment.) Pada perancangan ini menerapkan kontroler PID sebagai pengatur bukaan motor servo sehingga sesuai dengan nilai yang diinginkan. Nilai yang ingin dicapai yaitu $\mathrm{pH}$ 7 dan kekeruhan $<5 \mathrm{NTU}$ (nephelometric turbidity unit). Pada pengujian sistem didapat nilai set PID dengan $K p=3, \quad K i=1,5 \quad$ dan $K d=2$ yang dicapai untuk menetralkan air dengan rata-rata waktu selama 3,2 menit pada pengkondisian air asam. Sedangkan pada pengkondisian air basa, untuk menetralkan air dengan rata-rata waktu selama 4,2 menit. Untuk tingkat kekeruhan, telah didapat nilai yang dicapai untuk menjernihkan air dengan rata-rata waktu selama 6,6 menit pada pengkondisian air sampai 110 NTU yang diterapkan menggunakan kontroler PID. Untuk menetralkan air asam, digunakan bahan kimia Natrium Hidroksida $(\mathrm{NaOH})$ dengan konsentrasi 0,07 M(Molaritas). Sedangkan untuk menetralkan air basa, digunakan asam asetat $(\mathrm{CH} 3 \mathrm{COOH})$ dengan konsentrasi $0,06 \mathrm{M}$.
\end{abstract}

Kata kunci : Water treatment, sensor $\mathrm{pH}$, sensor turbiditas, motor servo, PID(Proporsional-IntegralDiferensial).

\section{PENDAHULUAN}

Air sangat penting dalam kehidupan manusia agar organ-organ yang terdapat di dalam tubuh bisa bekerja dengan baik. Manusia sangat membutuhkan air untuk bisa bertahan hidup, karena setiap harinya orang bisa memasukan air ke dalam tubuhnya namun disaat bersamaan juga kehilangan cairan melalui keringat, urin, feses bahkan saat bernafas hingga 1,5 per hari. Maka dari itu manusia sangat membutuhkan air minum sebagai kebutuhan Primer.(ISO., 1999)

Pada tahun 2016 telah dilakukan penelitian tentang "sistem penjernih air yang sudah sudah ada dengan judul Perancangan Sistem Pengontrolan Water Treatment pada Tingkat Kejernihan dan $\mathrm{pH}$ Air Skala Rumah Tangga” Menggunakan Fuzzy Logic Control oleh Rahmadiansyah. Pada penelitian tersebut dirancang suatu alat yang berfungsi untuk mengontrol dan memonitor jumlah injeksi tawas secara otomatis pada penjerniah air yang ada di PDAM mengunakan mikrokontroler ATMega 328 yang dihubungkan ke LCD(liquid crystal display). Sensor yang digunakan adalah sensor pendeteksi kekeruhan (geturbidity sensor) dan sensor pH (Rahmadiansyah., 2015).

Penelitian pada tahun 2014 tentang "sistem penjernihan air secara otomatis" pernah dilakukan oleh Diko Susanto, tentang alat penyaringan air kotor menjadi air bersih menggunakan mikrokontroler atmega 32. Dalam penelitiannya ini didapatkan hasil proses penyaringan air sungai dengan proses penjernihan dan persentase kekeruhan, kejernihan dan tingkat keberhasilan di tampikan pada LCD dan komputer sehingga proses penjernihannya dapat dievaluasi setiap saat (Susanto , Diko., 2014)

Pada tahun 2018 telah dilakukan penelitian tentang "Perancangan sistem pengontrolan water treatment pada tingkat kejernihan dan $\mathrm{pH}$ air untuk usaha tahu" dalam penelitianya menggunakan tawas agar tingkat kejernihan dan $\mathrm{pH}$ air lebih optimal serta diharapkan dapat menghasilkan air yang lebih banyak dengan setpoint yang diinginkan dengan waktu yang lebih cepat.(Siwi, Raka.,2018)

Selanjutnya pada tahun 2018 dilakukan penelitian tentang "Rancang bangun alat pendeteksi keasaman $(\mathrm{pH})$ air dengan SMS(short message service) Gateaway, GPS(global positioning system) dan ioT(internet of things) sebagai monitoring pada depot air minum" dalam penelitianya hasil pembacaan sensor pada air minum dapat di pantau melalui SMS, GPS dan ioT.(Darmawan, bayu., 2018) 


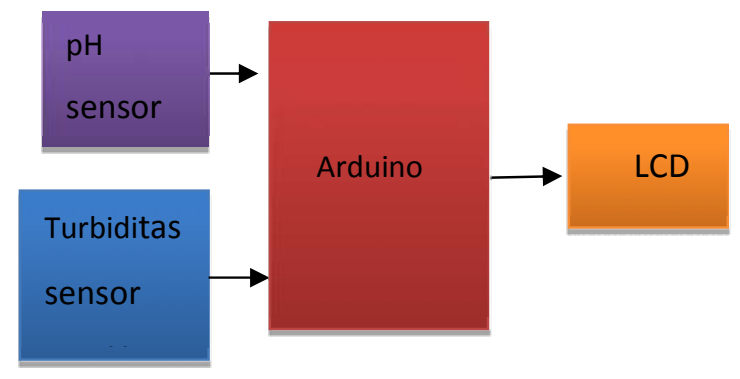

Gambar 2.1 Sistem Blok Diagram

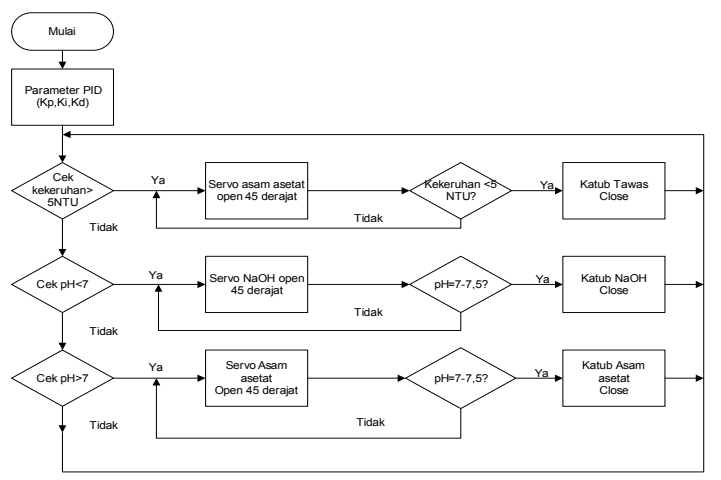

Gambar 2.2 Diagram Alir Secara Keseluruhan

Pada penelitian kali ini yaitu "perancangan sistem pengontrolan water treatment menjadi air layak minum menggunakan kontrol PID" diharapkan dapat mengurangi kesalahan pada penelitian sebelumnya dan menghasilkan air bersih yang memenuhi syarat air layak minum secara fisik dan kimiawi.

\section{Metode Penelitian}

Berdasarkan Gambar 2.1 sensor turbiditas dan sensor pH merupakan masukkan yang berupa nilai konsentrasi PM. Selanjutnya sistem control yang digunakan adalah mikrokontroler aduino UNO sehingga LCD sebagai tampilan keluaran dari sistem.

Gambar 2.1 menunjukkan diagram alir dari ssistem water treatment secara keseluruhan. Program diawali dengan sensor mendeteksi kondisi air dalam keadaan keruh maupun $\mathrm{pH}$ tidak netral.

\subsection{Rancangan Perangkat Keras}

Perancangan alat sistem pengontrolan tingkat kejernihan dan $\mathrm{pH}$ air merupakan alat yang mampu memberikan solusi dalam mendapatkan pasokan air layak minum. Gambar 2.2 menunjukkan perancangan sistem keseluruhan sistem.

Penelitian ini dimulai dengan tahapan perancangan dan perangkat keras yaitu motor servo, relay, power supply dll.

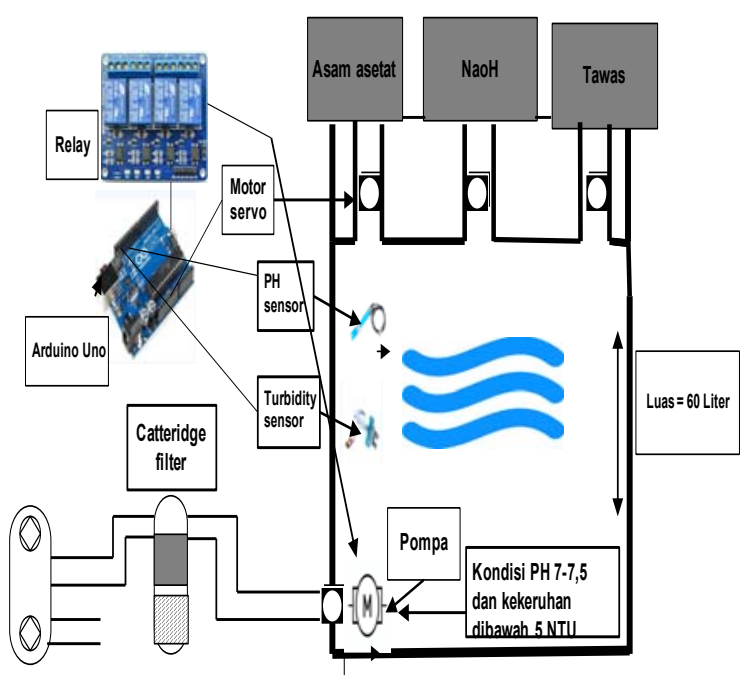

Gambar 2.3 Perancangan Sistem Keseluruhan

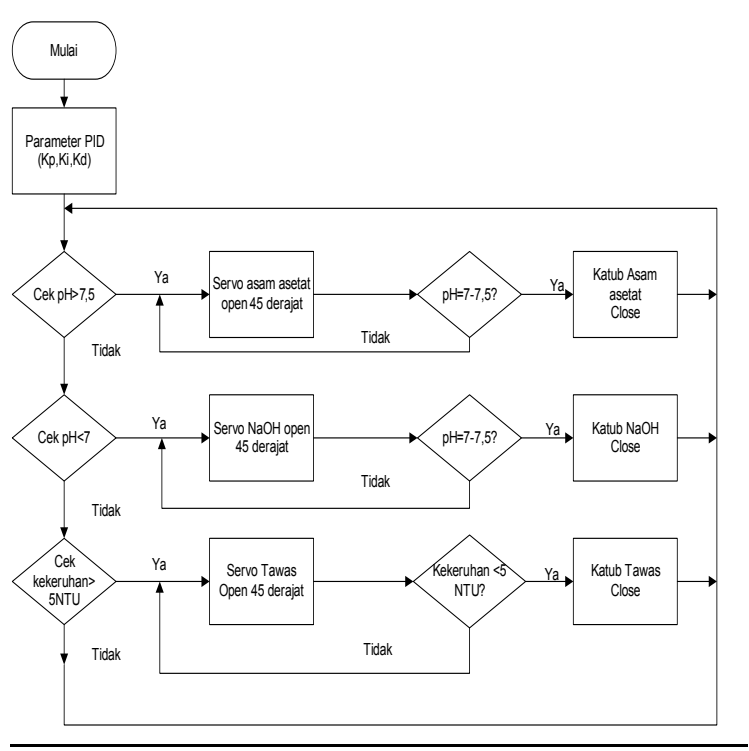

Gambar 2.4 Diagram Alir Sistem Perancangan

Dalam mekanisme pengaturan ini digunakan sample larutan yang berbeda untuk pembacaan $\mathrm{pH}$ dan kekeruhan. Pada perancangan alat asam asetat digunakan untuk menurunkan nilai $\mathrm{pH}$ air sedangkan $\mathrm{NaoH}$ yang mengandung basa kuat digunakan untuk menaikan nilai $\mathrm{pH}$ air yang dimana kedua laruan tersebut akan keluar secara otomatis Sampai air netral. Pada pengujian ini digunakan sampel larutan yang berbeda untuk pembacaan $\mathrm{pH}$ asam dan $\mathrm{pH}$ Basa.

Sedangkan untuk kekeruhan digunakan tawas sebagai penetralisir kekeruhan dengan melihat nilai kekeruhan harus sampai 5 NTU agar mendapat nilai kejernihan yang diinginkan maka sistem automasi akan bekerja membuka katup pada kotak tawas apabila tingkat kejernihannya lebih dari 5 NTU. 


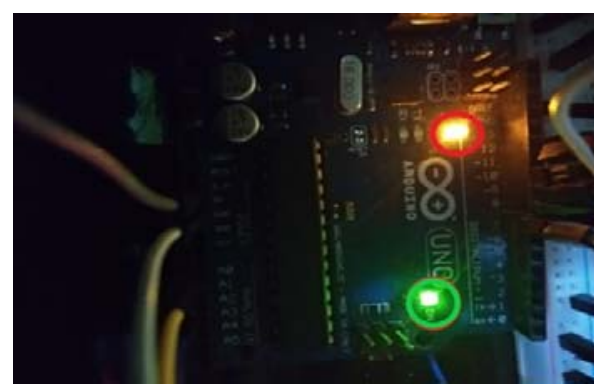

Gambar 4.1Tampilan lampu indicator "ON" pada Arduino uno Seperti yang ditunjukan pada Gambar 4.1 terdapat sebuah LED yang menyala. LED yang hidup merupakan indikator bahwa arduino keadaan hidup atau ON.

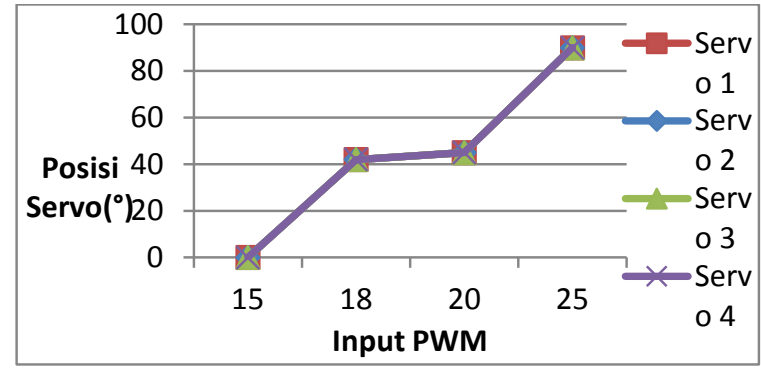

Gambar 4.2 Grafik pengujian motor servo

\section{Hasil dan Pembahasan}

Untuk memastikan sensitivitas sensor yang digunakan pada sistem Water treatment dapat berjalan dengan baik, perlu dilakukan beberapa tahapan pengujian pada komponen sistem yang digunakan. Hal ini dilakukan agar sensor yang terhubung tidak mengalami masalah, sehingga tidak mengganggu proses analisis rancangan Water treatment yang telah dibuat. Tahapan pengujian dimulai dari hasil pengujian mikrokontroler supaya bisa dioperasikan dengan baik.

\subsection{Hasil Pengujian Mikrokontroler}

Pengujian ini dilakukan dengan tujuan untuk mengetahui keadaan tiap-tiap pin atau port I/O yang ada pada arduino. Pada Gambar 4.1 terdapat 2 buah LED yang menyala, LED kuning pertama yang ditunjukkan dengan lingkaran hijau merupakan indikator bahwa arduino dalam keadaan hidup atau ON, sedangkan LED kuning yang kedua yang ditunjukkan dengan lingkaran merah adalah LED dengan jalur pin 13 dalam keadaan HIGH sesuai dengan program yang dimasukkan ke dalam arduino. Dengan demikian, dapat dikatakan arduino uno yang digunakan masih dalam kondisi yang baik.

\subsection{Hasil Pengujian Motor Servo}

Pengujian motor servo dilakukan untuk mengetahui apakah motor servo dapat bekerja menggerakan mekanik valve atau keran dengan baik atau tidak. Pengujian ini dilakukan dengan mengakses setiap motor servo dengan masukan nilai pwm.

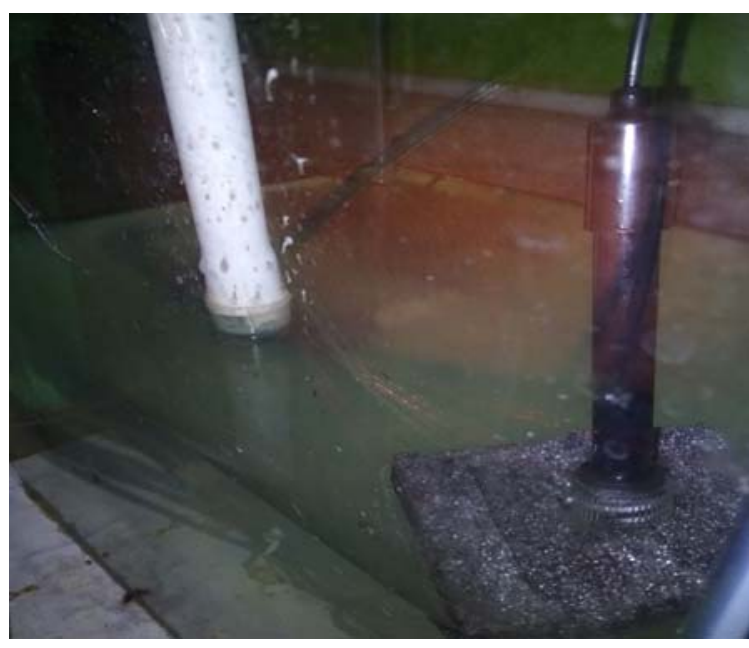

Gambar 3.3 Pengujian Sensor pH dan Turbiditas

Berdasarkan Gambar 3.2 dapat dilihat pada grafik menunjukkan semakin dinaikkan nilai PWM maka semakin meningkat besaran sudut servo yang terbuka. Pada pengujian servo ini dilakukan maksimal servo hanya $90^{\circ}$ karena valve yang dipakai maksimal putaranya $90^{\circ}$. Pada saat diberi masukan nilai pwm 15 , katub servo masih dalam keadaan tertutup sedangkan saat diberi masukan nilai pwm 25 katub servo terbuka penuh.

\subsection{Hasil Pengujian Sensor}

Pengujian ini bertujuan untuk mengetahui nilai selisih antara sensor dengan alat ukur yang digunakan dalam mendeteksi nilai $\mathrm{pH}$ dan tingkat kekeruhan air yaitu $\mathrm{pH}$ meter digital. Untuk pembanding sensor $\mathrm{pH}$ digunakan $\mathrm{pH}$ meter digital jenis ATC dengan rentang ukuran 0,0 hingga 14,0 dan tingkat ketelitianya adalah $\pm 0,1 \mathrm{pH}$. sedangkan untuk sensor turbiditas cara pengujiannya dilakukan dengan mengukur tingkat kekeruhan air yang berbeda-beda yaitu 25, 50, dan 100NTU(nephelometric turbidity unit).

Pada pengujian ini digunakan sampel larutan yang berbeda untuk pembacaan $\mathrm{pH}$ dan tingkat kekeruhan. Pada pengujian sensor $\mathrm{pH}$ dengan $\mathrm{pH}$ meter digital, asam asetat digunakan untuk menurunkan nilai $\mathrm{pH}$ air dan $\mathrm{NaOH}$ yang mengandung basa kuat digunakan untuk menaikan $\mathrm{pH}$ air yang dimana kedua larutan tersebut akan di tambahkan secara otomatis apabila air yang di uji mengandung $\mathrm{pH}$ asam maupun basa. Yang kemudian akan dicatat setiap selisih yang di dapat dari sensor $\mathrm{pH}$ dan $\mathrm{pH}$ meter digital dari setiap perubahan yang terjadi.

Untuk pengujian sensor turbiditas, dilakukan pengujian dengan memasukan tanah kedalam gelas ukur yang berisi air dengan volume $200 \mathrm{~mL}$. tanah yang ditambahkan sebanyak 2 sendok untuk 25 NTU, 4 sendok untuk 50 NTU, dan 7 sendok untuk 100 NTU. 


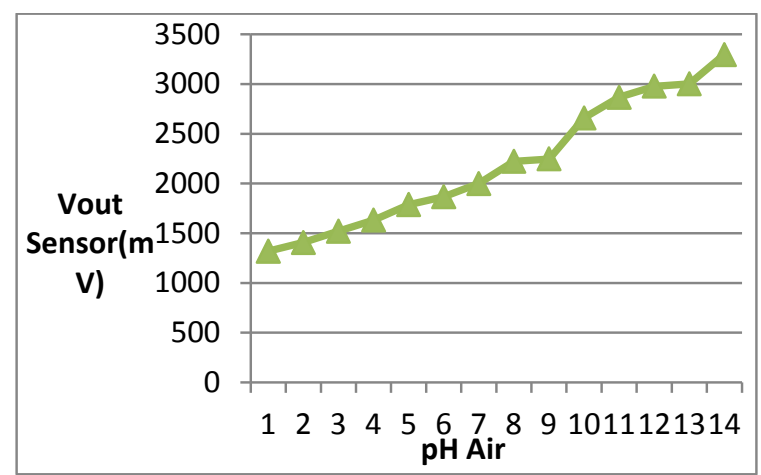

Gambar 3.4 Grafik Pengujian nilai pH sensor

\subsection{Pengujian Sensor pH}

Pengujian sensor $\mathrm{pH}$ dilakukan dengan mengukur nilai tegangan keluaran pada beberapa nilai keasaman $(\mathrm{pH})$ pada sampel air pengujian yang memiliki tingkat keasaman berbeda.

Dapat dilihat pada Gambar 3.4 untuk perbandingan sensor $\mathrm{pH}$ dengan tegangan keluaran dengan menggunakan larutan kimia $\mathrm{NaOH}$ untuk basa sedangkan asam asetat untuk asam dan juga mencari selisih antara pembacaan tegangan keluaran sensor yaitu didapat nilai error dari setiap percobaan yang dilakukan.

Berdasarkan Gambar 3.4 nilai pH ditentukan mulai dari 1 sampai dengan 14 kemudian diukur tegangan keluaran sensornya setiap kenaikan 1 nilai $\mathrm{pH}$. dari grafik diatas dapat dilihat nilai tegangan keluaran sensor yang terendah yaitu $1320 \mathrm{mV}$ untuk $\mathrm{pH}$ yang bernilai 1 sedangkan nilai tegangan keluaran sensor yang tertinggi yaitu $3297 \mathrm{mV}$ untuk pH 14. Dapat disimpulkan bahwa kenaikan nilai $\mathrm{pH}$ mengakibatkan semakin tinggi nilai tegangan keluaranya dengan laju yang mendekati linear. Hubungan antara kenaikan $\mathrm{pH}$ air dan tegangan keluaran sensor kurang linear disebabkan oleh sensor lebih peka terhadap $\mathrm{pH}$ yang $<7$ daripada $\mathrm{pH}>7$. Tujuan pengujian ini untuk mengetahui perubahan tegangan keluaran dengan setiap kenaikan $\mathrm{pH}$ yang diukur karena sensitivitas sensor akan menunjukkan seberapa jauh kepekaan sensor terhadap kuantitas yang diukur.

\subsection{Pengujian Sensor Turbiditas}

Pengujian sensor turbiditas adalah salah satu pengujian terpenting dalam perancangan dan pembuatan sistem penjernih, karena sensor merupakan komponen utama yang bertugas mengukur tingkat kekeruhan tertentu. Keakuratan sensor dalam membaca objek sangat mempengaruhi hasil pengukuran yang di dapat.

Pengujian dilakukan dengan pembuatan sampel air keruh yang selanjutnya dibaca oleh sensor yang hasilnya di tampilkan pada serial monitor dan LCD.

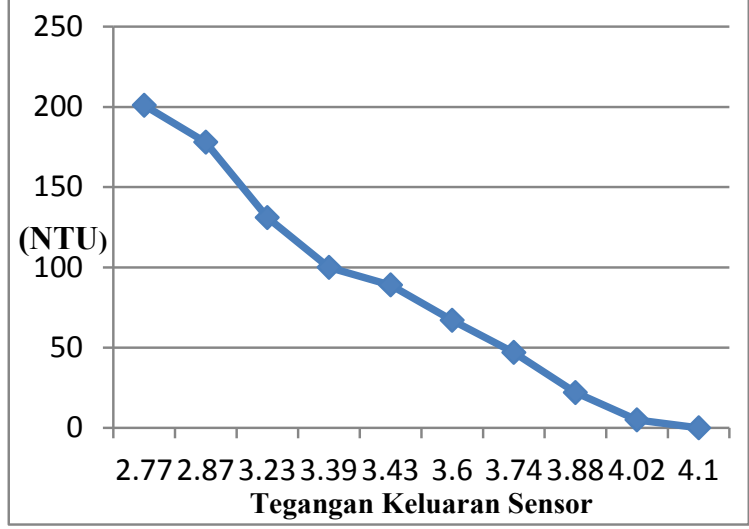

Gambar 3.5 Grafik Hasil pengujian sensor turbiditas

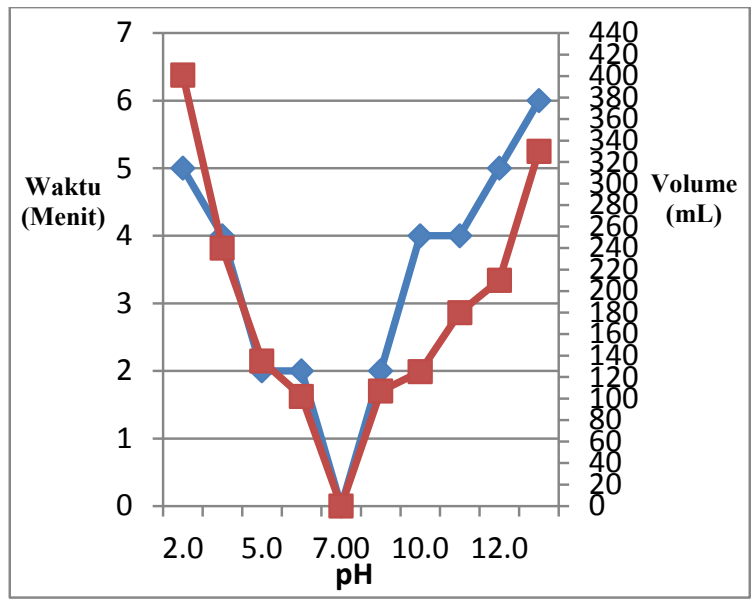

Gambar 3.6 Grafik durasi penetralan $\mathrm{pH}$

kemudian hasil pembacaan sensor tersebut dilakukan sebanyak 10 kali dengan tingkat kekeruhan dari 0 NTU hingga 200 NTU. Pada Gambar 3.5 berikut:

Dari data hasil pengujian pada Gambar 3.5 dapat dilihat nilai tegangan keluaran tegangan keluaran pada sensor turbiditas dengan nilai tingkat kekeruhan pada sampel air. Grafik 3.5 memperlihatkan bahwa semakin tinggi tingkat kekeruhan air maka nilai tegangan keluaran yang keluar dari sensor turbiditas semakin kecil tegangannya.

\subsection{Hasil Pengujian Pengkondisian pH}

Pada pengujian ini digunakan air larutan asam asetat dengan volume \pm 60 liter yang akan divariasikan nilai $\mathrm{pH}$ nya. Kemudian sistem akan dinyalakan untuk mengatur bukaan valve dengan motor servo yang di atur oleh kontroler PID dengan bukaan katub sebesar $45^{\circ}$ dari masing-masing valve asam maupun basa secara otomatis berdasarkan deteksi sensor untuk mengubah keadaan air yang awalnya asam maupun basa hingga berada pada nilai 7 dan berapa waktu yang dibutuhkan oleh sistem untuk menaikan ataupun menurunkan nilai 


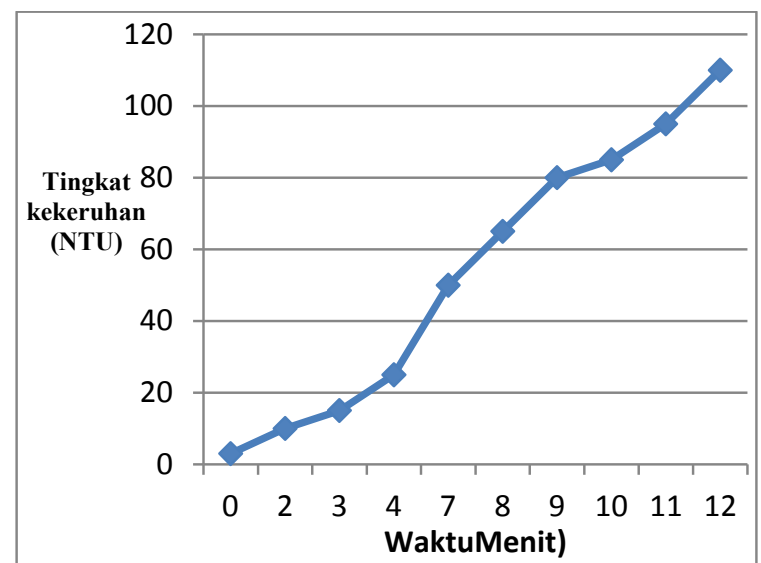

Gambar 3.7 Grafik Durasi valve saat diberi variasi kekruhan

$\mathrm{pH}$ air tersebut. Hasilnya dapat dilihat pada Grafik 3.6 yang menunjukan durasi valve saat di beri $\mathrm{pH}$ asam maupun basa.

Berdasarkan Gambar 3.6 menunjukkan bahwa dari 10 kali percobaan yang dilakukan, motor servo asam mampu melakukan pengkondisian $\mathrm{pH}$ air paling lama Selama 5 menit dengan volume air $401 \mathrm{~mL}$. Sedangkan motor servo basa mampu mengkondisikan air paling lama 6 menit dengan volume air $330 \mathrm{~mL}$.

\subsection{Hasil PengujianPengkondisian Kekeruhan}

Kadar kekeruhan maksimum untuk air bersih yang sudah sesuai dengan nilai referensi yang sudah ditentukan. Untuk mendapatkan kualitas air yang bersih maka nilai set point kekeruhan diatur sebesar 5 NTU. Jika sensor turbiditas membaca tingkat kekeruhan air lebih dari set point maka sistem penjernih akan aktif atau solenoid valve akan membuka katub tawas. Pengujian dilakukan dengan 10 variasi tingkat kekeruhan yang berbeda NTU untuk mengetahui pengkondisian air keruh sampai mencapai set point 5 NTU. Untuk hasil dan penjelasanya dapat dilihat pada Gambar 3.7

Gambar 3.7 merupakan data hasil pengujian dari 10 variasi tingkat kekeruhan yang berbeda. Dapat dilihat grafik menunjukan pembacaan sensor turbiditas terhadap waktu pengkondisian air keruh selama motor servo dalam keadaan terbuka $45^{\circ}$ untuk menurunkan tawas. Paling lama saat pengkondisian air keuh yaitu 12 menit. Dapat disimpulkan bahwa nilai rata-rata untuk menjernihkan air adalah 6,6 menit. Maka dapat dianalisa semakin tinggi tingkat kekeruhan air semakin lama juga waktu yang di butuhkan dari pembacaan sensor turbiditas untuk mengkondisikan air keruh yang terdeteksi.

\subsection{Tuning Dan Pengujian Respon PID}

Di dalam pengujian ini, dicari nilai $\mathrm{Kp}, \mathrm{Ki}$, dan $\mathrm{Kd}$ dicari agar mengetahui sensitivitas tiap sensor ketika

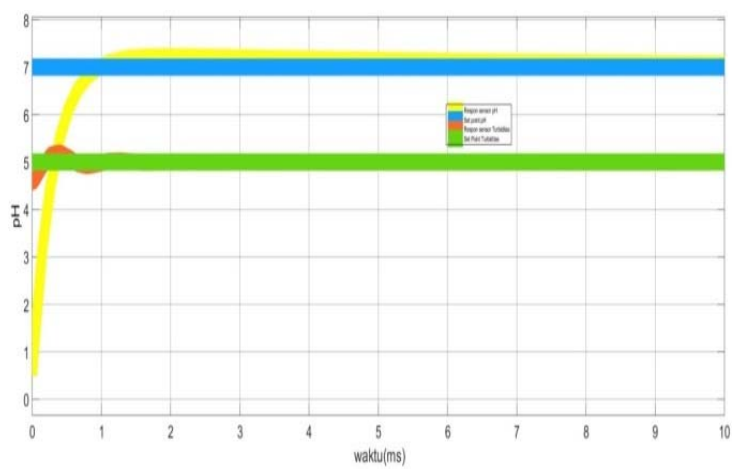

Gambar 3.8 Hasil respon penggabungan 2 Gelombang

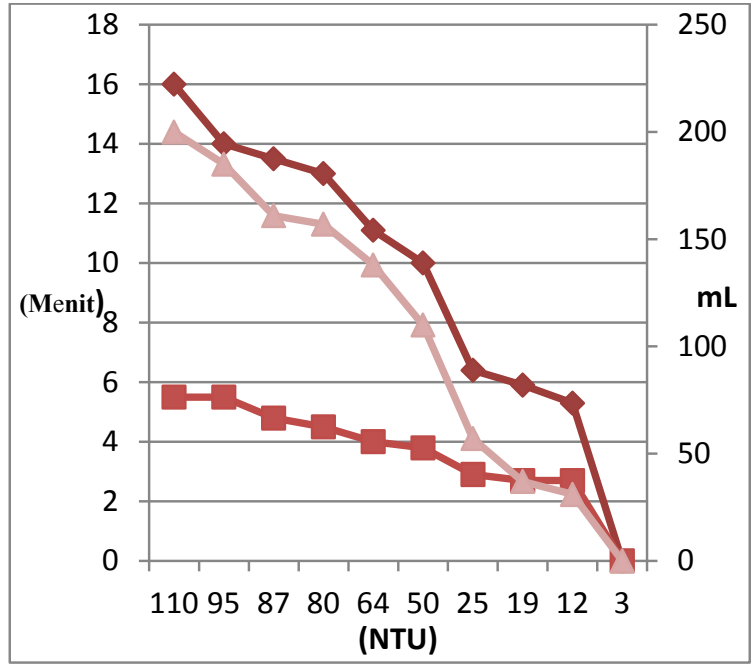

Gambar 3.9 Grafik Perbandingan durasi valve simulasi

diberi set point. Nilai set point berupa nilai $\mathrm{pH}$ dan tingkat kekeruhan sudah ditentukan pada simulasi MATLAB. Perancangan simulasi selanjutnya yaitu membuat simulasi sistem closed loop, dimana pada sistem ini akan dimasukan suatu block controller yang mendapatkan umpan balik dari respon sistem. Hasil dan penjelasan dapat dilihat pada Gambar 3.8 Diagram blok sistem closed loop dengan memasukan nilai $\mathrm{Kp}, \mathrm{Ki}$, dan Kd yang akan diuji dengan memasukan nilai satu persatu untuk dilihat seberapa besar kestabilan sensor dan mempercepat respon setelah dimasukan nilai yang dimasukan.

Dari Gambar 3.8 didapat hasil pengujian tingkat keasaman nilai yang paling baik dipilih yaitu $k p=3$, $K i=1.5$, dan $K d=2$ dan untuk Turbiditas sensor nilai yang paling baik yaitu $K p=0.8, K i=1,5$, dan $K d=0,5$.

\subsection{Pengujian Keseluruhan Hasil Perancangan}

Pengujian ini dilakukan untuk melihat hasil kerja dari sistem perancangan alat secara keseluruhan dalam mencapai set point kekeruhan air dan $\mathrm{pH}$ dari segi tingkat akurasi pencapaian set point hingga untuk

mengetahui error dari sistem. Set point kekeruhan air ditetapkan 0 NTU sampai 5 NTU dan pH adalah 7 untuk 
keasaman netral. Kemudian dibuatlah grafik perbandingan antara saat durasi valve aktif dengan dengan respon sensor pada simulasi PID

Dari Gambar 3.9 dapat dilihat perbandingan durasi valve aktif dengan respon turbiditas sensor pada simulasi. Pada durasi valve aktif nilai yang dikeluarkan lebih tinggi dari simulasi. Oleh sebab itu sensor sangat lama merespon proses penjernihan. Sedangkan pada saat simulasi PID, waktu yang dicapai lebih cepat karena pada saat simulasi tidak diberi gangguan. Dari perbandingan tersebut didapat nilai rata-rata error $6,87 \%$.

\section{Penutup}

\subsection{Kesimpulan}

Secara keseluruhan dari Perancangan tuning dan pengujian sistem dapat ditarik Kesimpulan, antara lain :

1. Pada perancangan ini telah dibuat sebuah sistem kontrol Water treatment yang dapat digunakan untuk mengontrol keadaan air sesuai dengan syarat air layak minum yaitu secara fisik dan kimiawi.

2. Pada pengujian sistem didapat nilai set PID dengan $K p=3, K i=1,5$ dan $K d=2$ yang dicapai untuk menetralkan air dengan rata-rata waktu selama 3,2 menit pada pengkondisian air asam. sedangkan pada pengkondisian air basa untuk menetralkan air dengan rata-rata waktu selama 4,2 menit. Untuk tingkat kekeruhan, telah didapat nilai yang dicapai untuk menjernihkan air dengan rata-rata waktu 6,6 menit pada pengkondisian air sampai 110 NTU yang diterapkan menggunakan kontroler PID. Untuk menetralkan air asam, digunakan bahan kimia Natrium Hidroksida $(\mathrm{NaOH})$ dengan konsentrasi 0,07 M(Molaritas). Sedangkan untuk menetralkan air basa, digunakan asam asetat $(\mathrm{CH} 3 \mathrm{COOH})$ dengan konsentrasi $0,06 \mathrm{M}$.

3. Pengujian keseluruhan sistem hasil perancangan menunjukan bahwa sistem mampu mencapai set point kekeruhan dan $\mathrm{pH}$ air untuk memenuhi syarat air layak minum dengan nilai set point $\mathrm{pH} 7$ dan kekeruhan $<5$ NTU yang telah diterapkan pada kontroler PID. Maka dari itu, diperoleh hasil pembanding antara aktual dengan simulasi pada MATLAB didapatkan hasil pembanding dengan rata-rata error sebesar $6,87 \%$ untuk tingkat kekeruhan dan 5,88\% untuk tingkat keasaman.

\section{DAFTAR PUSTAKA}

[1] International Standards Organization. (1999). “ Water Quality-Determination of Turbidity”. ISO 7027, Geneva, Switzerland.

[2] Rahmadiansyah. (2015). "Pengontrolan water treatment kejernihan dan ph skala rumah tangga”. Bengkulu: Universitas Bengkulu.

[3] Susanto, Diko. 2014. Alat Penyaringan Air Kotor Menjadi Air Bersih Menggunakan Mikrokontroller Atmega 32. Program Studi Teknik Informatika Fakultas Ilmu Komputer Universitas Dehasen Bengkulu.

[4] Raka ,siwi (2018). "Perancangan system pengontrolan water treatment pada tingkat kejernihan dan pH air untuk usaha tahu”. Bengkulu: Universitas Bengkulu.

[5] Bayu ,darmawan (2018). "Rancang bangun alat pendeteksi keasaman $(p H)$ air dengan SMS Gateaway, GPS dan ioT”. Bengkulu: Universitas Bengkulu. 